\title{
HYDROTHERMAL SYNTHESIS OF Mn-DOPED TiO 2 WITH A STRONGLY SUPPRESSED PHOTOCATALYTIC ACTIVITY
}

\author{
HIDROTERMALNO SINTENTIZIRAN Z Mn DOPIRAN TiO 2 \\ Z MOČNO INHIBIRANO FOTOKATALITSKO AKTIVNOSTJO
}

\author{
Maja Lešnik¹, Dejan Verhovšek ${ }^{1}$, Nika Veronovski' ${ }^{1}$, Mitja Gračner¹, Goran Dražić \\ Kristina Žagar Soderžnik ${ }^{3}$, Mihael Drofenik ${ }^{4}$ \\ ${ }^{1}$ Cinkarna Celje, d.d. Inc., Kidričeva 26, SI-3001 Celje, Slovenia \\ ${ }^{2}$ National Institute of Chemistry Slovenia, Hajdrihova 19, 1001 Ljubljana, Slovenia \\ ${ }_{3}^{3}$ Jožef Stefan Institute, Department for Nanostructured Materials, Jamova cesta 39, 1000 Ljubljana, Slovenia \\ ${ }^{4}$ University of Maribor, Faculty of Chemistry and Chemical Engineering, Smetanova ulica 17, 2000 Maribor, Slovenia \\ maja.lesnik@cinkarna.si
}

Prejem rokopisa - received: 2017-01-26; sprejem za objavo - accepted for publication: 2018-01-16

doi:10.17222/mit.2017.012

\begin{abstract}
Nanocrystalline rutile $\mathrm{TiO}_{2}$ doped with various amounts of manganese $(\mathrm{Mn})$ atoms was prepared using a hydrothermal synthesis route and a polycrystalline $\mathrm{TiO}_{2}$ precursor. The diffuse reflectance spectra of the highly doped rutile nanocrystallites display a notable red shift in the band-gap transition. The absorbing band edge moved to the visible range when the Mn content in the rutile nanocrystallite exceeded $0.4 \%$. The doped rutile nanocrystallites were analysed using X-ray powder diffraction (XRD), transmission electron microscopy (TEM), high-resolution transmission electron microscopy (HRTEM) and UV-Vis spectroscopy. The Kubelka-Munk band-gap approximation was used to examine the narrowing of the band gap in comparison with the pure rutile $\mathrm{TiO}_{2}$ nanocrystallites. The doped rutile nanocrystallites displayed a remarkable decrease in the photocatalytic activity due to the formation of recombination sites induced by Mn ions incorporated into the crystal structure of the $\mathrm{TiO}_{2}$.

Keywords: suspension, $\mathrm{TiO}_{2}$, rutile, doped with inorganic metal elements, UV absorber
\end{abstract}

$\mathrm{Z}$ uporabo hidrotermalne sinteze in polikristalininične rutilne oblike nanodelcev $\mathrm{TiO}_{2}$, smo pripravili nanokristalinične rutilne delce, dopirane z Mn. S pomočjo UV-VIS difuzivno refleksijske spektroskopije smo zaznali izrazit premik absorpcijskega roba $\mathrm{k}$ valovnim dolžinam vidne svetlobe. Energijska vrzel z Mn dopiranega $\mathrm{TiO}_{2}$ se je z naraščanjem koncentracije dopanta ožala. $\mathrm{Za}$ analizo dopiranih rutilnih $\mathrm{TiO}_{2}$ nanodelcev smo uporabili rentgensko praškovno difrakcijo (XRD), elektronsko mikroskopijo (TEM, HRTEM), UV-Vis spektroskopijo, kalkulacijo energijskih vrzeli s Kubelka Munk približkom. Pri merjenju fotokatalitske aktivnosti, z metodo degradacije izopropanola v alkohol, smo ugotovili, da dopiranje rutilne oblike $\mathrm{TiO}_{2} \mathrm{z} \mathrm{Mn}_{\mathrm{n}}$ povzroči inhibicijo fotokatalitske aktivnosti, kar smo pripisali tvorbi rekombinacijskih centrov, ki nastanejo pri dopiranju $\mathrm{z}$ Mn ioni $\mathrm{v}$ kristalno rešetko $\mathrm{TiO}_{2}$.

Ključne besede: suspenzija, $\mathrm{TiO}_{2}$, s kovinami dopiran rutil, UV absorber

\section{INTRODUCTION}

Titanium dioxide $\left(\mathrm{TiO}_{2}\right)$ crystallites are very efficient at scattering incident light and are therefore applied in some of the finest white pigments. In addition, $\mathrm{TiO}_{2}$ has a wide range of photocatalytic applications in the protection of the environment, where an enhanced photocatalytic activity is desired. On the other hand, $\mathrm{TiO}_{2}$ is an excellent UV absorber and shows no UV-induced degradation over time. ${ }^{1}$ For this reason it is also used in a variety of applications where it acts as an UV-protective material, including various coatings, sunscreens and plastics. Using $\mathrm{TiO}_{2}$ as a UV-protective material requires that the material is modified in such a way as to prevent the formation of free radicals upon the absorption of UV photons, which are otherwise preferred in environmentprotection applications. ${ }^{2}$ Thus, the free radicals that are involved in a number of potential health concerns, such as skin aging, must be reduced as much as possible. One possibility for reducing the photocatalytic activity of $\mathrm{TiO}_{2}$ is a nanocrystallite surface coating with inorganic oxides that are transparent with respect to UV photons, such as $\mathrm{SiO}_{2}$ and $\mathrm{Al}_{2} \mathrm{O}_{3}$, so isolating the surface from adsorbents, particularly moisture. ${ }^{3}$ However, a thin layer on the crystallite surfaces has not been shown to be efficient in terms of significantly reducing the photocatalytic activity of the material.

Another option to suppress the photocatalytic activity of $\mathrm{TiO}_{2}$ is doping the material with transition-metal ions (TMIs), which induced defects, and that function mainly as carrier-recombination centres when migrating from the inside to the surface of the photocatalyst and represent the key to a low photocatalytic activity, for instance, in the case of manganese doping. ${ }^{4-7}$

Recently, some works were published that report on the enhanced photocatalytic activity of Mn-doped $\mathrm{TiO}_{2} \cdot{ }^{8} 9$ Here, the superior reactivity might be ascribed to the anatase crystallites' morphology and structure as one of the main reasons for the improved photocatalytic activity in these samples. To the best of our knowledge the inhibition of photocatalytic activity in pure rutile Mn-doped samples prepared by hydrothermal synthesis, 
from prefabricated $\mathrm{TiO}_{2}$, has not been reported yet. Here, we must emphasize that the hydrothermal method was crucial in synthesizing the Mn-doped rutile phase, which strongly inhibits the photocatalytic activity.

\section{EXPERIMENTAL PART}

\subsection{Preparation method}

The hydrothermal synthesis of Mn-doped rutile $\mathrm{TiO}_{2}$ nanocrystallites was performed in a Teflon-lined, stainless-steel autoclave with a volume of $80 \mathrm{~mL}$. To prepare the $\mathrm{TiO}_{2}$-doped sample the reactor was loaded with a $50-\mathrm{mL}$ aqueous suspension of polycrystalline rutile $\mathrm{TiO}_{2}$ nanocrystallites provided by Cinkarna Celje, Inc. having a mass concentration of $60-150 \mathrm{~g} / \mathrm{L}$ (calculated as $\mathrm{TiO}_{2}$ ) and $1 \%$ of mass fractions (based on $\mathrm{TiO}_{2}$ content) of manganese chloride $\left(\mathrm{MnCl}_{2}, 96 \% \mathrm{w} / \mathrm{w}\right.$, Merck). The mixture of polycrystalline rutile $\mathrm{TiO}_{2}$ nanocrystallites and dopant was then stirred for at least $15 \mathrm{~min}$. The autoclave was put into a preheated oven and was hydrothermally treated at $180{ }^{\circ} \mathrm{C}$ for $24 \mathrm{~h}$. At the end of the heating process the autoclave was taken out of the oven and left to cool at room temperature. The as-prepared product was diluted with distilled water, washed on a laboratory centrifuge (MPW 350 - Med. Instruments, High brushless centrifuge, $4000 \mathrm{~min}^{-1}, 20 \mathrm{~min}$ ). The washing was performed until the conductivity of the material was less than $900 \mu \mathrm{S} / \mathrm{cm}$. The final product was an aqueous suspension of doped rutile having a $10 \%$ of mass fraction of monosized $\mathrm{TiO}_{2}$ nanocrystallites with a light-brown colouration. Samples with anticipated concentrations of $\mathrm{Mn}(0.4 \%, 0.8 \%$ and $2 \%)$ of mass fractions, labelled as samples: B, C and D, were also prepared by the same process by varying the content of added $\mathrm{MnCl}_{2}$. The sample $\mathrm{A}$ was prepared using the same process, but without the addition of $\mathrm{MnCl}_{2}$ as a dopant.

\subsection{Characterization of samples}

The morphology and size of the particles were examined with a transmission electron microscope (TEM, Jeol JEM-2100, Jeol Ltd., Tokyo, Japan). To prepare the TEM specimens, the samples were ultrasonically dispersed and the suspension was collected using carbon-supported copper grids. The presence of the manganese was verified using energy-dispersive X-ray spectroscopy (EDXS). The crystal structure, the concentration of $\mathrm{Mn}$ and the valence state of the titanium in sample $B$ (nominally $0.8 \%$ of mass fractions manganese-doped $\mathrm{TiO}_{2}$ ) were characterized with probecorrected scanning transmission electron microscopy (STEM, Jeol ARM 200 CF) and electron-energy-loss spectroscopy (EELS, Gatan Quantum ER dual).

The crystallinity of the particles was examined using X-ray diffraction (XRD) performed on a Cubi X PRO PW 3800 instrument (PANanalytical) $\left(\mathrm{Cu}-K_{\alpha}\right.$ radiation $(\lambda=0.15418 \mathrm{~nm}))$. In order to acquire the $\mathrm{TiO}_{2}$ powders for the X-ray powder diffraction (XRD) investigation, the suspensions were dried at $80{ }^{\circ} \mathrm{C}$, ground and the powder was pressed into pellets that were used to perform the measurements.

The UV-Vis diffuse reflectance spectra were collected on an Agilent-Cary 300 UV-Vis spectrophotometer equipped with an integrating sphere (Varian Inc., USA).

The measurements of the photocatalytic activity were performed in a sealed gas-solid reactor at room temperature and a relative humidity of $60 \%$, utilizing FT-IR spectroscopy (Spectrum BX model Perkin Elmer spectrometer). The model pollutant was isopropanol in the gas phase. During the photocatalytic reaction the isopropanol oxidizes into acetone and subsequently into carbon dioxide and water under UV irradiation (Xe lamp, $300 \mathrm{~W}$ ). The light imitates the solar spectrum and emits both ultraviolet (UV) and visible (VIS) light. The reactor is at a distance of $4 \mathrm{~cm}$ from the lamp. The samples were dried under ambient conditions and prepared by milling $50 \mathrm{mg}$ of the material. To perform the measurements, $20 \mu \mathrm{L}$ of isopropanol was injected into the system. This volume represents around $2000 \mathrm{mg} / \mathrm{L}$ of gas phase of the isopropanol in the system. The amount and ratio of isopropanol and the formed acetone were monitored in real time. The evaluation of the photocatalytic activity is based on the acetone-formation kinetics and is given in $\mathrm{mg} / \mathrm{L} \mathrm{h} .^{10}$

\section{RESULTS AND DISCUSSION}

\subsection{Hydrothermal synthesis}

Hydrothermal synthesis is one of the best methods for producing pure oxide nanocrystalline materials. Among the various hydrothermal methods, hydrothermal precipitation is suitable for the synthesis of nanocrystallite material using a polycrystalline precursor and transforming it into a nanocrystalline material with a controlled morphology and composition. During this investigation the dissolution of the precursor, polycrystalline rutile, and afterwards a precipitation in the presence of the dopant, was applied in order to transform it into nanocrystalline material with a controlled morphology and composition.

After the dissolution and subsequent diffusion of $\mathrm{TiO}_{2}$ in the presence of hydrated $\mathrm{Mn}$ ions to the precipitation locations, the precipitation from the solution on the doped rutile nanocrystallites is a relatively sluggish process that determines the final morphology of the crystallites and the concentration of the dopant. The amount of dopant that was not incorporated during the $\mathrm{TiO}_{2}$ precipitation was washed away at the end of the procedure.

In solution the $\mathrm{TiO}_{2}$ exist as six-fold coordinated structural units $\left(\mathrm{TiO}_{6}\right)$ that undergo condensation to become the octahedra that bond via corner- and 
Table 1: The nominal concentration vs. real concentration determined by EDXS, BET specific surface area, Scherrer's crystallite size of the prepared samples and the measured band gap

\begin{tabular}{|c|c|c|c|c|c|}
\hline Sample* & $\begin{array}{c}\text { Nominal Mn } \\
\text { concentration }(w / \%)\end{array}$ & $\begin{array}{c}\text { Real Mn } \\
\text { concentration }(w / \%)\end{array}$ & $\begin{array}{c}\text { Specific surface area } \\
\left(\mathrm{m}^{2} / \mathrm{g}\right)\end{array}$ & $\begin{array}{c}\text { Crystallite size } \\
(\mathrm{nm})\end{array}$ & $\begin{array}{c}\text { Band gap } \\
(\mathrm{eV})\end{array}$ \\
\hline A & - & - & 70.1 & 27.8 & 3.01 \\
\hline B & 0.4 & $0.30 \pm 0.1$ & 69.5 & 29.9 & 2.98 \\
\hline C & 0.8 & $0.90 \pm 0.1$ & 78.3 & 31.7 & 2.90 \\
\hline D & 2.0 & $1.50 \pm 0.1$ & 93.1 & 21.8 & 2.87 \\
\hline
\end{tabular}

edge-sharing to form the final crystal structure. Hence, the fundamental structural units are $\left(\mathrm{TiO}_{6}\right)$ octahedrons, having different modes of arrangement and links, depending on the particular crystal form of the $\mathrm{TiO}_{2}$. In the rutile form the $\left(\mathrm{TiO}_{6}\right)$ octahedra link by sharing an edge along the c-axis to form chains. During the precipitation process oxygen coordinated $\mathrm{Mn}$ units incorporate into the rutile by replacing the $\left(\mathrm{TiO}_{6}\right)$ octahedrons in a doped rutile structure. However, the incorporation of coordinated Mn complex ions covering various oxidation states and coordination aggravate the incorporation of the manganese. Thus, the incorporation of $\mathrm{Mn}$ at higher nominal concentrations is not straight forward, but exhibits a lag with regards to the nominal concentration of the manganese, Table 1.

\subsection{The crystalline phase of particles}

The XRD patterns of Mn-doped $\mathrm{TiO}_{2}$ with different nominal concentrations $(0,0.2,0.8,2.0) \%$ of $\mathrm{Mn}$ in the $\mathrm{TiO}_{2}$ are shown in Figure 1. The XRD peaks confirm the presence of a rutile crystal structure in all the samples. No manganese-rich phase was identified in the XRD patterns, even when the doping level concentration was as high as $2.0 \%$ of mass fractions.

The average crystallite size was determined using diffraction-peak (100) broadening and Scherrer's formula based on the FWHM (Full Width at Half Maximum) of the XRD peaks. The determined crystallite size is shown in Table 1. For up to $0.8 \%$ of mass fractions of dopant the crystallite size is more or less around $30 \mathrm{~nm}$. After that, at $2.0 \%$ of mass fractions of dopant, the diffraction-peak broadening indicates a decrease in the crystallite size accompanied by an increase of the specific surface, Table 1. Thus, with up to $2.0 \%$ of mass fractions of manganese addition in the nanocrystallites the morphology of the crystallites did not change significantly.

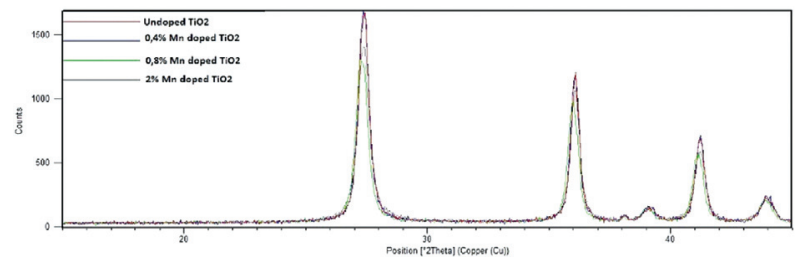

Figure 1: XRD patterns of undoped and Mn-doped $\mathrm{TiO}_{2}$ samples with different Mn contents

\subsection{The morphology of the doped $\mathrm{TiO}_{2}$ particles}

TEM images of the undoped $\mathrm{TiO}_{2}$ and $0.8 \%$ of mass fractions of $\mathrm{Mn}$-doped $\mathrm{TiO}_{2}$ nanocrystallites are shown in Figure 2. The hydrothermally synthesized, doped, rutile $\mathrm{TiO}_{2}$ nanocrystallites have an oval/spherical morphology and are uniform in size. From the TEM images no significant difference in the morphology between the synthesized products, i.e., $0.8 \%$ of mass fractions of Mn-doped $\mathrm{TiO}_{2}$ and undoped $\mathrm{TiO}_{2}$, can be seen, in agreement with the XRD patterns, which show a comparable crystallite size up to $0.8 \%$ of mass fractions of $\mathrm{Mn}$, Table 1.
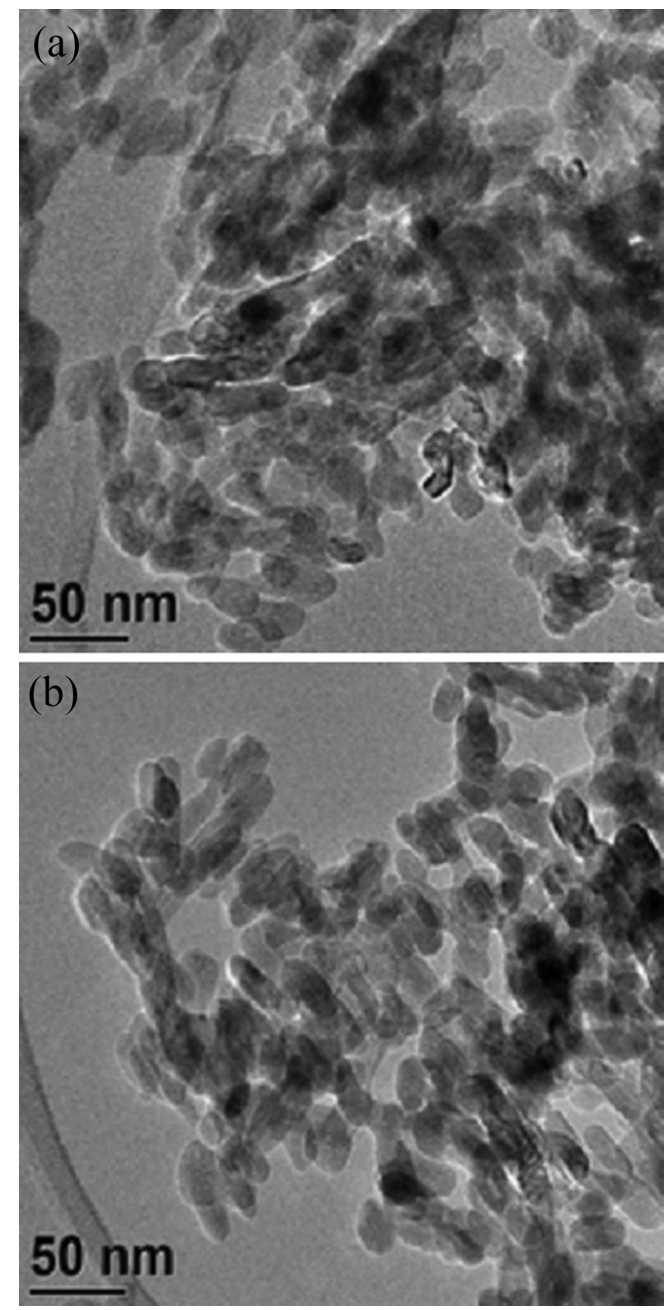

Figure 2: TEM image of: a) undoped sample $\mathrm{A}$ and b) sample $\mathrm{C}$ with a nominal concentration of $0.8 \%$ of mass fractions of $\mathrm{Mn}$ 
The average crystallite size and the specific surface data in Table 1 show that the morphology of samples D doped with a nominal concentration of $2.0 \%$ of mass fractions of $\mathrm{Mn}$ are different than the other samples in the sequence. They exhibit a smaller crystallite size and a higher specific surface area. An increase in the nominal concentration of $\mathrm{Mn}$ in the samples up to $0.8 \%$ of mass fractions is accompanied by a notable increase in the reflectance from $20 \%$ to about $50 \%$, as well as a bandgap decrease from $3.01 \mathrm{eV}$ to $2.90 \mathrm{eV}$ in sample $\mathrm{C}$.

The STEM-EELS analyses of sample $\mathrm{C}$ is presented in Figure 3. The doped crystallites have an oval-spherical morphology and are uniform in size (a). No amorphous Mn-rich oxide phase was found on the surface of the particles, which indirectly confirms the incorporation of the $\mathrm{Mn}$ phase into the $\mathrm{TiO}_{2}$ crystal lattice. The presence of a precipitated dopant on the particle surface is a relatively common phenomenon. Evidently, the concentration of $0.8 \% \mathrm{Mn}$ is the limit for fully incorporating the dopant into the crystal lattice, which is confirmed by the UV-Vis reflectance spectra, where the absorption of the higher amount of dopant ( $2 \%$ of mass fractions of $\mathrm{Mn}$ ) is negligible. At the edges of the rutile nanocrystallites the reconstruction of the surface structure took place. In these areas the presence of $\mathrm{Ti}^{3+}$ was observed using EELS. The observation is quite interesting, because it is not usual to find such an arranged structure containing $\mathrm{Ti}^{3+}$ on the surface of a particle. Further investigations are necessary in order to find an appropriate explanation. The excellent match of the experimental and the simulated electron-diffraction patterns shown in Figure 3b confirms the presence of individual rutile nanocrystallites and no anatase or brookite crystal modifications were detected. The EELS analysis identified the presence of $\mathrm{Mn}$, but due to the
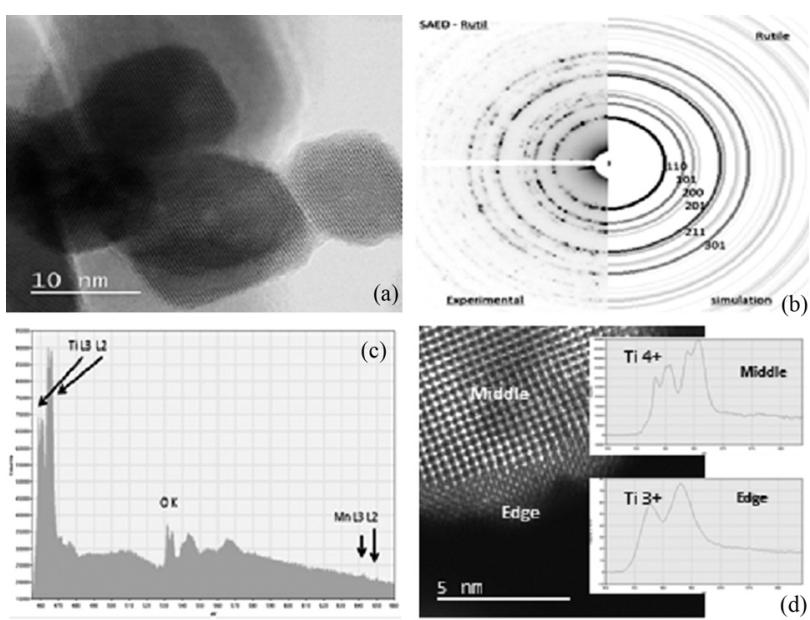

Figure 3: BF-STEM image: a) of hydrothermally treated $\mathrm{TiO}_{2}$ nanocrystallites with $0.8 \%$ of mass fractions of $\mathrm{Mn}, \mathrm{b}$ ) experimental and simulated selected-area electron-diffraction pattern (SAED) for rutile, c) EELS spectrum where traces of Mn can be seen, d) HAADF-STEM micrograph of rutile nanocrystallites where an approximately 1-nm-thick phase can be seen at the edge of the particle, the edge contains a large amount of $\mathrm{Ti}^{3+}$, based on the EELS spectra (insets) very low concentration it was not possible to determine the valence state of this Mn. Finally, the Mn phase is not uniformly incorporated inside the particles as not all the EELS spectra from the different nanoparticles contain Mn edges.

\subsection{UV-Vis diffuse reflectance spectra}

The influence of doping on the UV/Vis spectra properties of the rutile $\mathrm{TiO}_{2}$ is clear from Figure 4. The Mn-doped samples exhibit a notable difference in their colour, which depends on the dopant concentration and extends from light-to-dark yellow to a rose (skin-like) colour. As can be seen in Figure 4, the reflectivity dependence of the wavelength of the undoped $\mathrm{TiO}_{2}$ has a typical sharp edge of reflection at around $420-400 \mathrm{~nm}$, while the reflection capacity of the visible-light region is relatively poor at that wavelength. Using the relation $E(\mathrm{eV})=h c / \lambda(\mathrm{nm})=1236 / / \lambda(\mathrm{nm})$ we obtain, for the measured band gaps of the samples, values of 2.94-3.06 eV, which corresponds to an electron excitation from the VB to the $\mathrm{CB}$ of the rutile. Besides, for the determination of the band-gap energy, the Kubelka-Munk procedure was used. ${ }^{11,12}$ The extrapolated values are shown in Table 1.

In comparison, from the reflectivity spectra of the Mn-doped samples, Figure 4, it is clear that there is a significant reflection of visible light. ${ }^{13-16}$ In addition, two absorption edges are present in the reflective spectra. The primary absorption edge contributes to the reflectance at short wavelengths of the visible spectra, while the secondary absorption edge extends into the lowest wavelengths of the visible light spectra, in agreement with previous reports. ${ }^{7-9}$ The intensity of both absorption edges changes when increasing the Mn-doping concentration. Moreover, it is also possible that the Mn doping even induces the reflection of IR light, which is in agreement with Shao's report. ${ }^{8}, 16,17$ When the doping level reached a nominal concentration of $0.8 \%$, the optical reflection was shifted into the infrared spectral range. In addition, samples doped with a nominal concentration of $0.8 \%$ of mass fractions and $2.0 \%$ of mass

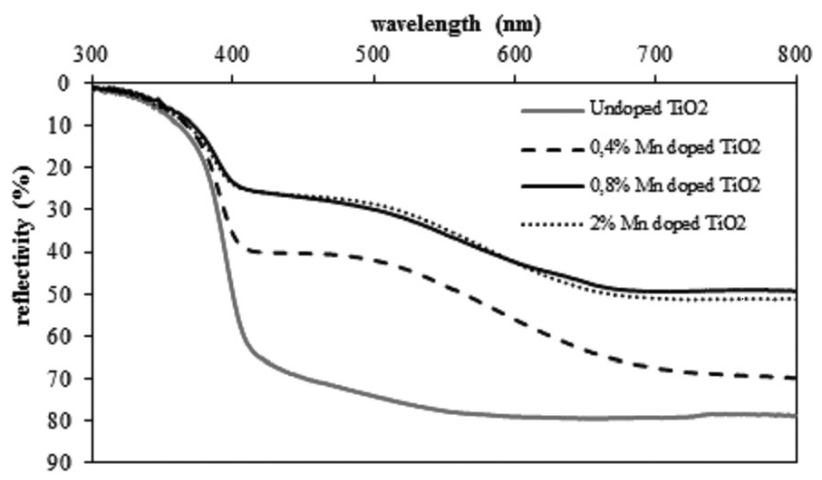

Figure 4: UV/Vis reflectance spectra of the undoped $\mathrm{TiO}_{2}$ and the $\mathrm{TiO}_{2}$ doped with different $\%$ of mass fractions of $\mathrm{Mn}$ ions, indicated in the figure 


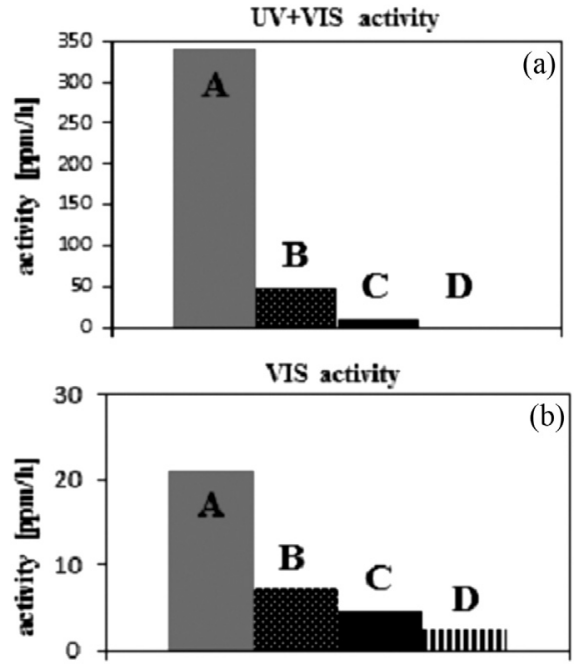

Figure 5: photocatalytic activity of undoped $\mathrm{TiO}_{2}$ and $\mathrm{TiO}_{2}$ doped with different amounts of $\mathrm{Mn}$ ions $\left(\mathrm{A}-\right.$ undoped $\mathrm{TiO}_{2}, \mathrm{~B}-0.2 \%$ of mass fractions of $\mathrm{Mn}$ doped $\mathrm{TiO}_{2}, \mathrm{C}-0.8 \%$ of mass fractions of $\mathrm{Mn}$ doped $\mathrm{TiO}_{2}, \mathrm{D}-2 \%$ of mass fractions of $\mathrm{Mn}$ doped $\mathrm{TiO}_{2}$ ) under a) $\mathrm{UV}+\mathrm{Vis}$ irradiation and $\mathrm{b}$ ) Vis irradiation

fractions exhibited a reflectivity of $50 \%$ at a wavelength of $800 \mathrm{~nm}$. As we can see in Figure 4, the reflectivities of the samples C and D were actually the same. Similar results were described by Deng for a nominal concentration of $0.8 \%$ of mass fractions and $2.0 \%$ of mass fractions doped samples, respectively, where the samples were synthesized using the sol-gel method and achieved a limiting dopant concentration of $12 \%$ with a $75 \%$ absorbance in the Vis absorption spectra. ${ }^{8}$

\subsection{Photocatalytic activity measurements}

To evaluate the photocatalytic activity of the undoped and $\mathrm{Mn}$-doped $\mathrm{TiO}_{2}$, the photocatalytic degradation of isopropanol under UV+VIS and Vis irradiation was studied. The results of the photocatalytic activity are presented in Figure 5, based on the acetone-formation kinetics, and are given in $\mu \mathrm{L} / \mathrm{L} \mathrm{h}$. It is clear that under $\mathrm{UV}+\mathrm{Vis}$ irradiation the photocatalytic activity of the Mn-doped $\mathrm{TiO}_{2}$ drastically decreased to near-zero values. The reduced photocatalytic activity of the Mn-doped $\mathrm{TiO}_{2}$ particles under UV light was also reported by Chauhan. ${ }^{18}$ When the Mn-doped $\mathrm{TiO}_{2}$ particles were exposed to visible light, the same results were obtained. The pure, undoped $\mathrm{TiO}_{2}$ acts as a visible-light photocatalyst, but when the $\mathrm{TiO}_{2}$ particles were doped with $\mathrm{Mn}$ ions, the inhibition of the photocatalytic activity occurs.

The photocatalytic-activity inhibition of the Mn-doped $\mathrm{TiO}_{2}$ was also established in Chang's work and in the research of Wakefield. ${ }^{4,7}$ Manganese ions are p-type dopants that are incorporated into the $\mathrm{Ti}^{4+}$ lattice sites and have a crucial effect on the activity, because they serve as $\mathrm{Mn}^{3+/ 4+}$ doping trap centres (recombination centres), which have both occupied and unoccupied energy levels within the band gap, trap electrons and holes on the same sites and rapidly annihilate the trapped carriers through intra-atomic relaxation. ${ }^{4,8}$ Since the Mn ions serve as recombination centres it should be pointed out that the photocatalytic activity of doped samples decreases when the concentration level of the dopant is increased. ${ }^{5}$

In addition, the electronic structure, the coordination number, the electronegativity, and the size of the dopant ions are all major influencing parameters that affect the formation of free radicals, having an impact on the effectiveness of Mn doping with respect to blocking the photocatalytic activity.

It is interesting to note that the manganese is a very effective inhibitor of the photocatalytic activity and even a relatively small dopant level, of only $0.8 \%$ of mass fractions of $\mathrm{Mn}$, nearly completely blocks the photocatalytic activity of rutile nanocrystallites in the UV region and to a relatively large extent also in the VIS part of the spectra. Less prone to photocatalytic reactions is also the relatively high dopant concentration level of $2.0 \%$ of mass fractions of Mn where the smaller crystallites are formed (sample D, Table 1), in spite of a higher specific surface area. The manganese ions have the appropriate characteristics to successfully inhibit the photocatalytic activity, particularly when they are incorporated into the interior of the matrix and the doping-induced defects are operating as carrier-recombination centres when they migrate from the inside of the photocatalyst to the surface. $^{5}$

\section{CONCLUSIONS}

Mn-doped rutile $\mathrm{TiO}_{2}$ nanocrystallites that demonstrate a strong reduction in photocatalytic activity were successfully prepared using the hydrothermal method. The average crystallite particle size is around $30 \mathrm{~nm}$; however, this decreases at the $2 \%$ of mass fractions of dopant concentration level. This could indicate the maximum concentration level of the dopant ions incorporated into the crystal structure. On the surface of the particle no amorphous $\mathrm{Mn}$ oxide phase is detected, which indirectly confirms the incorporation of the Mn phase into the $\mathrm{TiO}_{2}$ crystal structure. The diffuse reflectance spectrum of the Mn-doped $\mathrm{TiO}_{2}$ has two absorption edges and displays a red shift in the optical absorption range, which increases with the $\mathrm{Mn}$ content and narrows the band gap. The Mn-ions-doped $\mathrm{TiO}_{2}$ nanocrystallites, which can display a red shift in the band-gap transition, reduce strongly the photocatalytic activity.

\section{Acknowledgment}

This work is partially financially supported by the Ministry of Education, Science and Sport of the Republic of Slovenia under the contract 34/2013-SOF. 


\section{LEŠNIK et al.: HYDROTHERMAL SYNTHESIS OF Mn-DOPED TiO 2 WITH A STRONGLY SUPPRESSED ...}

\section{REFERENCES}

${ }^{1}$ J. Winkler, Titanium Dioxide, Vincentz, Hanover, 2003

${ }^{2}$ B. Faure, G. Salazar-Alvarez, A. Ahniyaz, I. Villaluenga, G. Berriozabal, Y. R. De Miguel, L. Bergström, Dispersion and surface functionalization of oxide nanoparticles for transparent photocatalytic and UV-protecting coatings and sunscreens, Science and Technology of Advanced Materials, 14 (2013), doi:10.1088/1468-6996/14/2/ 023001

${ }^{3}$ T. A. Egerton, The influence of surface alumina and silica on the photocatalytic degradation of organic pollutants, Catalysts, 3 (2013), 338-362, doi:10.3390/catal3010338

${ }^{4} \mathrm{~S}$. Chang, W. Liu, The roles of surface-doped metal ions (V, Mn, Fe $\mathrm{Cu}, \mathrm{Ce}$ and $\mathrm{W}$ ) in the interfacial behaviour of $\mathrm{TiO}_{2}$ photocatalysts, Applied Catalysis B: Environmental, 156-157 (2014), 466-475

${ }^{5}$ Z. Li, W. Shen, W. He, X. Zu, Effect of Fe-doped $\mathrm{TiO}_{2}$ nanoparticle derived from modified hydrothermal process on the photo catalytic degradation performance on methylene blue, Journal of Hazardous Materials, 155 (2008), 590-594, doi: 10.1016/j.jhazmat.2007.11.095 ${ }^{6}$ G. Liu, L. Wang, H. Gui Hang, H.-M. Cheng, G. Q. Lu, Titaniabased photocatalysts-crystal growth, doping and heterostructuring, Journal of Materials Chemistry, 20 (2010), 831-843, doi:10.1039/ b909930a

${ }^{7}$ G. Wakefield, S. Lipscomb, E. Holland, J. Knowland, The effects of manganese doping on UVA absorption and free radical generation of micronized titanium dioxide and its consequence for the photostability of UVA absorbing organic sunscreen components, Photochemical \& Photobiological sciences, 3 (2004), 648-652, doi:10.1039/ b403697b

${ }^{8}$ Q. R. Deng, X. H. Xia, M. L. Guo, Y. Gao, G. Shao, Mn-doped $\mathrm{TiO}_{2}$ nanopowders with remarkable visible light photocatalytic activity, Materials Letters, 65 (2011), 2051-2054, doi:10.1016/j.matlet.2011. 04.010

${ }^{9}$ X. H. Xia, L. Lu, A. S. Walton, M. Ward, X. P. Han, R. Brydson, J. K. Luo, G. Shao, Origin of significant visible-light absorption properties of Mn-doped $\mathrm{TiO}_{2}$ thin films, Acta Materialia, 60 (2012), 1974-1985, doi:10.1016/j.actamat.2012.01.006
${ }^{10}$ T. Marolt, A. Sever Škapin, J. Bernard, P. Živec, M. Gaberšček, Photocatalytic activity of anatase-containing facade coatings, Surface and Coatings Technology, 206 (2011), 1355-136, doi:10.1016/ j.surfcoat.2011.08.053

${ }^{11}$ S. Valencia, J. M. Marin, G. Restrepo, Study of the bandgap of synthesized titanium dioxide nanoparticles using the sol-gel method and a hydrothermal treatment, The Open Materials Science Journal, 4 (2010), 9-14

${ }^{12}$ V. Džimbeg-Malčič, Ž. Bararić-Mikočević, K. Itrić, Kubelka - Munk theory in describing optical properties of paper, Technical Gazette, 18 (2011), 117-124

${ }^{13}$ H. Feng, M. Zhang, L. E. Yu, Hydrothermal synthesis and photocatalytic performance of metal-ions doped $\mathrm{TiO}_{2}$, Applied Catalysis A: General, 413-414 (2012), 238-244, doi:10.1016/j.apcata.2011. 11.014

${ }^{14}$ M. Xue, L. Huang, J. Q. Wang, Y. Wang, L. Gao, J. Zhu, Z. Zou, The direct synthesis of mesoporous structured $\mathrm{MnO}_{2} / \mathrm{TiO}_{2}$ nanocomposite: a novel visible-light active photocatalyst with large pore size, Nanotechnology, 19 (2008), 185604, doi:10.1088/0957-4484/19/ 18/185604

${ }^{15}$ Y. Chen, X. Ma, Preparation of visible-light active Mn-doped $\mathrm{TiO}_{2}$ photocatalyst and its photodegradation of methylene blue from solution, Advanced Materials Research Vols., 989-994 (2014), 513-535

${ }^{16} \mathrm{G}$. Shao, Red shift in manganese and iron-doped $\mathrm{TiO}_{2}$ : A DFT+U analysis, The Journal of Physical Chemistry. C, 113 (2009), 6800-6808, doi:10.1021/jp810923r

${ }^{17}$ G. Shao, Q. Deng, L. Wan, M. Guo, X. Xia, Y. Gao, Molecular design of $\mathrm{TiO}_{2}$ for gigantic red shift via sublattice substitution, Journal of Nanoscience and Nanotechnology, 10 (2010) 7092-7096, doi: 10.1166/jnn.2010.2767

${ }^{18}$ R. Chauhan, A. Kumar, R. P. Chaudhary, Structural and photocatalytic studies of $\mathrm{Mn}$ doped $\mathrm{TiO}_{2}$ nanoparticles, Sprectrochimica Acta Part A: Molecular and biomolecular spectroscopy, 98 (2012), 256-264, doi:10.1016/j.saa.2012.08.009 